\title{
Moisture sorption isotherms and isosteric heat sorption of habanero pepper (Capsicum chínense) dehydrated powder
}

\section{Luna-Flores, M${ }^{a^{*}}$, Peña-Juarez M.Ga , Bello-Ramírez A.Ma , Telis-Romero $J^{\text {b }}$, Luna- Solano Ga}

${ }^{a}$ División de estudios de posgrado e investigación, Instituto Tecnológico de Orizaba, Av. Oriente 9 No 852, C.P 94320, Orizaba Veracruz., México.

${ }^{\mathrm{b}}$ Food engineering and technology department, State University of Sao Paulo, São José do Rio Preto, 15054-000 São Paulo, Brazil

*E-mail of the corresponding author: moonluna2009@live.com

\begin{abstract}
Moisture sorption isotherms of the habanero pepper powder were determined using the Dynamic Vapor Sorption (DVS) method at 20, 25, 35, 45 and $55^{\circ} \mathrm{C}$ in a range of water activity from 0.10 to 0.90 at which the processes of drying, packing and storage of habanero pepper are developed. The sorption capacity decreased with increasing temperature at a given water activity and the sorption isotherms showed a sigmoid form (Type II). The hysteresis phenomenon was observed in the sorption isotherms at all temperatures studied and it was more pronounced at temperatures high. The experimental sorption curves were fitting to the GAB, BET and Oswin models. It was concluded that the models that best describe the adsorption and desorption data for habanero pepper dehydrated powder were the GAB and Oswin models. The isosteric heat of water sorption was calculated with the moisture content data in equilibrium. The desorption isotherms present a higher isosteric heat in relation to the adsorption isotherms. In both, the isosteric heat decreased as the moisture content increased.
\end{abstract}

Keywords: Habanero pepper dehydrated powder; Convective drying; Moisture sorption isotherms; Mathematic models 
Moisture sorption isotherms and isosteric heat sorption of habanero pepper (Capsicum chinense) dehydrated powder

\section{Introduction}

Habanero pepper is a variety of red pepper most popular in the Mexican territory, it has a high moisture content (> $80 \%$ wet base) and the main characteristics of the habanero are color (carotenoids), aroma and mainly the pungencia due to the capsaicinoids $[1,2]$. Therefore, the export and conservation of fresh fruit have several disadvantages because habanero pepper is very perishable and has a limited shelf life. Convective drying is one of the most popular and efficient heat and mass transfer process that allows to prolong and preserve the useful life of foods by reducing water activity $\left(\mathrm{a}_{\mathrm{w}}\right)$ and decreasing moisture content [3]. The state of water plays an important role in the preservation of food. The degree of sorption of water from a food system depends on the vapor pressure of the water present in the food sample and in the surroundings. The equilibrium moisture content (EMC) is obtained when the vapor pressure of water present in food is equal to the vapor pressure of the surroundings. The water activity $\left(\mathrm{a}_{\mathrm{w}}\right)$ of a food is an equilibrium property of the water and its constituents present, which defines as the ratio of the partial pressure of the water vapor in the food $(p)$ and the partial pressure pure water vapor $\left(p_{o}\right)$ at the same temperature, as shown in equation 1 :

$$
a_{k p}=\frac{p}{p_{0}}=\frac{H R}{100}
$$

The relationship between EMC and aw in a range of values at a constant temperature generates an evaluation tool very useful called "Moisture sorption isotherm", which relates the amount of water adsorbed or desorbed in equilibrium. An adsorption isotherm refers to the behavior of dehydrated foods, which tend to adsorb water against the surrounding relative humidity to have equilibrium pressures. While a desorption isotherm refers to the behavior of hydrated foods, which tend to eliminate water to have equilibrium conditions at a given temperature. These behaviors depend on the interaction between water and food components. Sorption isotherms provide information for a variety of processing applications and product stability, such as prediction of moisture transfer, determination of product stability and shelf life, storage conditions, selection of packaging systems [3, 4, 5]. Therefore, the aim of this study was to analyze the isotherms (adsorption and desorption) of the habanero pepper dehydrated powder.

\section{Materials and Methods}

\subsection{Raw material and convective drying of habanero pepper}

Habanero pepper was obtained from the city of Orizaba, Veracruz, Mexico. The selected fruits showed an orange color and similar size (4-7 cm length, 3-5 cm width). Samples of habanero pepper were cut into slices $0.6 \mathrm{~cm}$ wide and placed on metal trays of a convective 
dryer (Polinox SEM-2). The convective drying process was performed at a temperature of $60^{\circ} \mathrm{C}$ and at an air velocity of $1.5 \mathrm{~m} / \mathrm{s}$ for $360 \mathrm{~min}$ until moisture $\geq 0.05 \mathrm{~g}$ water/g dry solids is constant. The data obtained from drying at $60{ }^{\circ} \mathrm{C}$ was plotted as moisture ratio (MR) according to the equation 2 :

$$
M R=\frac{X-X_{e}}{X_{0}-X_{e}}
$$

Where $X$ is the moisture content at any time $t, X_{e}$ is the equilibrium moisture and $X_{0}$ is the initial moisture. These experimental sets $(M R, t)$ were fitted to different empirical models from literature applicable to agricultural products: Page, Newton, Henderson \& Pabis, Logarithmic and Wang \& Sing. These equations for drying kinetics are indicated below (equations 3 to 7 ), respectively.

$$
\begin{gathered}
M R=e^{-k t} \\
M R=e^{-k t^{i n}} \\
M R=a \cdot e^{-k t} \\
M R=c+a \cdot e^{-k t} \\
M R=1+a \cdot t+b \cdot t^{2}
\end{gathered}
$$

Where $\mathrm{n}, \mathrm{a}, \mathrm{b}$ and $\mathrm{c}$ are constants of the models, and $t$ is any time in the drying kinetics.

\subsection{Physicochemical analysis}

During the convective drying process of dehydrated habanero pepper, the evolution curves of water activity and color difference were performed. The water activity was determined at $25 \pm 1{ }^{\circ} \mathrm{C}$ using a water activity meter (AQUALAB series 3 model TE). The moisture content ( $\mathrm{g}$ water/ $\mathrm{g}$ dry solids) of habanero pepper was measured with a halogen thermobalance (OHAUS, model MB35).

\subsection{Moisture sorption isotherms}

Habanero peppers were milled in a manual pulverizer of blades at laboratory scale, model GRT-20B of 3000 Watts and $25000 \mathrm{rpm}$ for $3 \mathrm{~min}$ to obtain samples of habanero pepper powder to analyze moisture sorption isotherms. The sorption isotherms (adsorption and desorption) were determined by a vapor sorption analyzer (AquaLab VSA), which consists of an equipment that automatically generates moisture sorption isotherms in foods, 
Moisture sorption isotherms and isosteric heat sorption of habanero pepper (Capsicum chinense) dehydrated powder

allowing the determination of the complex relationship between aw at each reading and the EMC of the sample at a constant temperature. The isotherms were determined at 20, 25, 35, 45 and $55^{\circ} \mathrm{C}$. The VSA equipment generates the static isotherms in equilibrium by the Dynamic Vapor Sorption (DVS) method, which consists of monitoring the weight change of the sample as it is exposed to different controlled relative humidities. The sample is maintained at each humidity for a period of time until the sample reaches a steady state weight change, where the objective is to achieve the equilibrium between the aw and the controlled humidity inside the generator chamber. The experimental sorption isotherms of the habanero chili powder were performed in duplicate.

\subsection{Prediction of mathematical models}

The mathematical models GAB (Guggenheim \& Anderson de Boer), BET (Branauer, Emmett \& Teller) and Oswin represented by equations 8, 9 and 10 were used to adjust and predict the experimental values of sorption isotherms (adsorption and desorption).

$$
\begin{gathered}
E M C=\frac{C K X_{m} a_{w}}{\left(1-K a_{w}\right)\left(1-K a_{w}+C K a_{w}\right)} \\
E M C=\frac{C X_{m} a_{w}}{\left(1-a_{w}\right)\left(1-a_{w}+C a_{w}\right)} \\
E M C=A\left[\frac{a_{w}}{\left(1-a_{w}\right)}\right]^{\bar{z}}
\end{gathered}
$$

Where: A, B, C and $\mathrm{K}$ are constants of the models, $\mathrm{a}_{\mathrm{w}}$ is the water activity, EMC is the equilibrium moisture content ( $\mathrm{g}$ water/g dry solids) and $\mathrm{X}_{\mathrm{m}}$ is the moisture content in the monolayer (g water/g dry solids).

\subsection{Net isosteric heat of sorption}

The net isosteric heat of sorption was determined from moisture sorption using the equation 11, derived from the Clausius Clapeyron equation:

$$
\ln \left(a_{w}\right)=-\left(\frac{q_{s t}}{R}\right) \frac{1}{T}+C_{1}
$$

Where $a_{W}$ is the water activity, $T$ is the absolute temperature $(\mathrm{K}), q_{s t}$ is the net isosteric heat of sorption $\left(\mathrm{J} \mathrm{mol}^{-1}\right), \mathrm{R}$ is the gas constant $\left(\mathrm{J} \mathrm{mol}^{-1} \mathrm{~K}^{-1}\right)$.

\subsection{Results and discussion}


Figure 1 and 2 show the adjustment of the mathematical models of the drying kinetics and the evolution curves of $\mathrm{a}_{\mathrm{w}}$ of habanero pepper during drying as a function of time, observing that the $\mathrm{a}_{\mathrm{w}}$ and moisture content of the fresh fruit is relatively high. However, when the drying process is performed, the values of moisture content and $\mathrm{a}_{\mathrm{w}}$ decreased significatly. A food with an $\mathrm{a}_{\mathrm{w}}$ less than 0.60 and moisture content low is considered safe and stable during storage in relation to microbial growth [6]. The $a_{w}$ is considered a parameter for the conservation and stability of food as well, it has been used as an important variable to evaluate and reduce the rate of microbial growth, chemical reactions, lipid oxidation and enzymatic activity in the food [5].

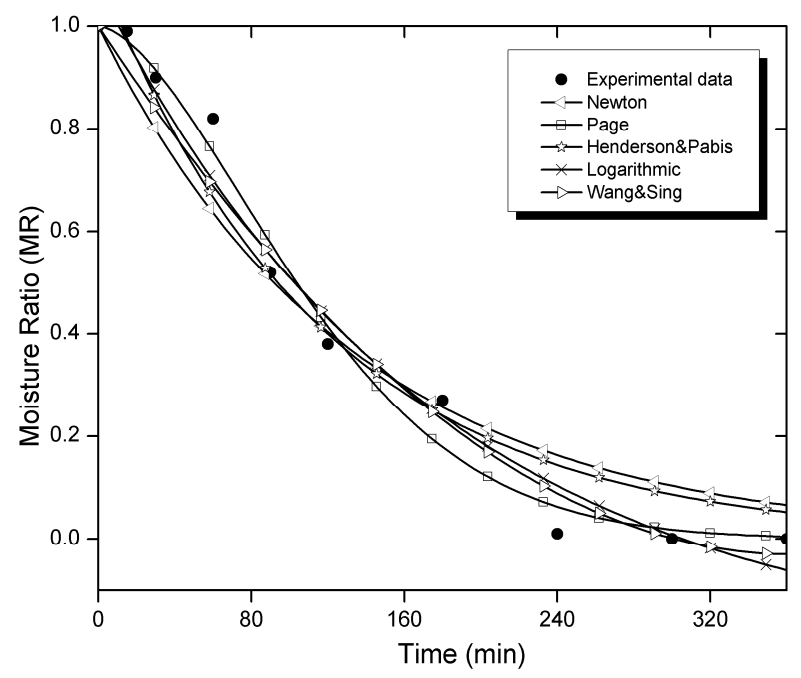

Figure 1. Fitting of the experimental data with the different models tested

Figure 1 shows the experimental data points obtained from temperature $60{ }^{\circ} \mathrm{C}$ of the drying process together with the plots corresponding to the fittings obtained for all the models tested. It is observed that the Page and Newton curves are better describing the habanero pepper drying process. On the other hand the models of Henderson \& Pabis and Logarithmic do not represent the initial state ( $\mathrm{t}=0 \mathrm{~min}$ ), while the Wang \& Singh model does not exemplify the final state $(\mathrm{t}=360 \mathrm{~min})$. However, the best model to describe this drying kinetics process is the Page model because it shows a sigmoidal shape in the curve. In Figure 2(a), it is possible to observe how the moisture behavior follows a sigmoidal shape, which is characteristic of the drying process. The initial moisture content was $83.59 \%$ and the final content $1.56 \%$. Regarding water activity in Figure 2(b), shows also a sigmoidal shape and it is possible to reach a safe range (below 0.6) at time $180 \mathrm{~min}$. 
Moisture sorption isotherms and isosteric heat sorption of habanero pepper (Capsicum chínense) dehydrated powder

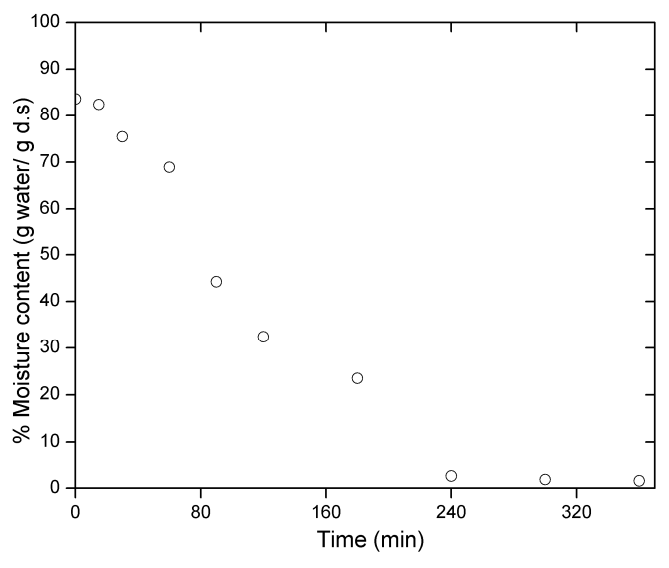

a)

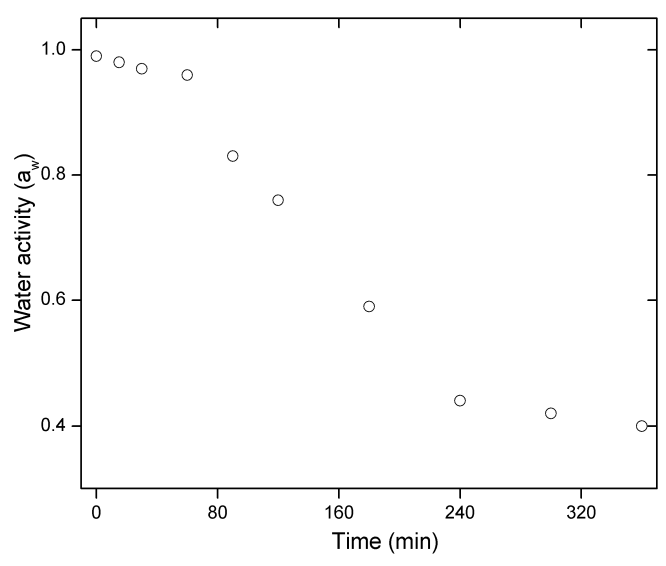

b)

Figure 2. Drying curves for physicochemical parameters of habanero pepper: a) moisture content and b)water activity

The shapes of the adsorption and desorption curves of habanero pepper dehydrated powder showed a behavior similar to the five temperatures $\left(20,25,35,45\right.$ and $\left.55^{\circ} \mathrm{C}\right)$ studied and presented a non-linear trend type II (sigmoid) typical shape for most foods [7], which is shown in Figure 3. As the temperature increases, the EMC decreased to a constant water activity, this change generates that the water molecules are activated due to a change in the increase in the pressure of the water vapor inside the particles of habanero pepper powder through a state of excitation, becoming less stable and consequently accelerating the moisture transfer of the food around it [8]. In addition, it was observed a simultaneous increase of the EMC because the food particles are saturated by water molecules according to an incremented in the values of water activity at a constant temperature. This is due to the decrease in the degree or capacity of sorption of water in habanero pepper powder when the temperature increases. In the process of desorption, it was observed that the high and intermediate values of the water activities in the desorption curves of habanero pepper powder present a remarkable decrease of the EMC due to the dissipation of the water molecules present in the surfaces towards the surroundings. This indicates the influence of temperature on the desorption isotherms. However, it is also shown that the desorption curves between low values of $\mathrm{a}_{\mathrm{w}}(0.3-0.1)$ and the EMC are very close to each other. This means that the water molecules bind more firmly and the enthalpy of vaporization is greater due to the transition of the water that is strongly attached to the capillaries of habanero pepper powder. 


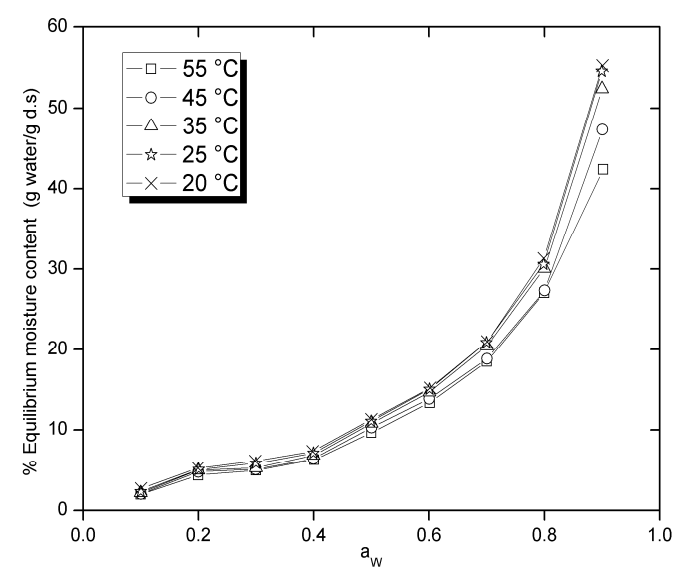

a)

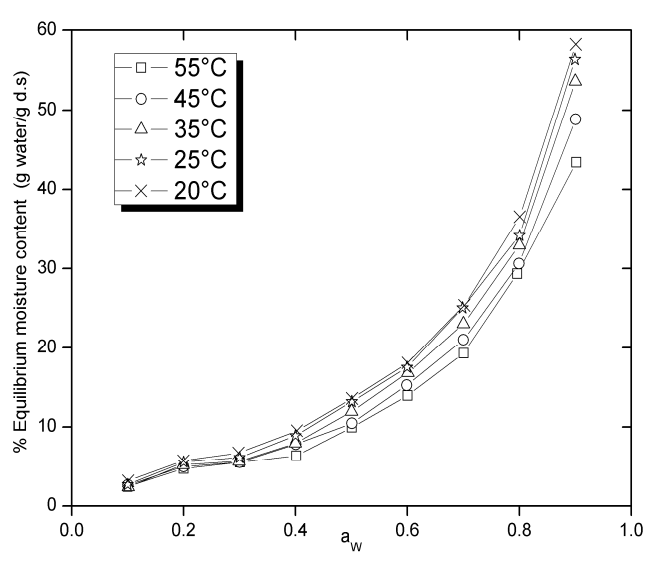

b)

Figure 3. Isotherms of habanero pepper: a) adsorption and b) desorption

The GAB, BET and Oswin models were fitted to evaluate the behavior of moisture sorption isotherms and the goodness of fit for each model was evaluated according to the coefficient of determination (R2), sum of the square error (SSE) and the residual mean square error (RMSE). The results of the non-linear regression analysis are presented in Table 1. The best fits were obtained with the GAB and Oswin models with a R2>0.995 and R2>0.987, $\mathrm{SSE}<7.705$ and 19.91 , for $\mathrm{RMSE}<1.133$ and 1.687 respectively for the sorption isotherms of habanero pepper dehydrated powder. However, the GAB model presents an advantage due to it presents theoretical bases and the value of moisture content in the monolayer $(\mathrm{Xm})$ whereby it is best model that empirical model of Oswin. The net isosteric heat of sorption (qst) decreased with increasing moisture content. The higher values of qst were found at low moisture contents, this can be explained by the fact that the water molecules are tightly bound to the monolayer structure and food components; and therefore, the quantity of energy needed to adsorb or desorb these water molecules is very high. However, a rapid decrease in sorption isosteric heat was observed when the moisture content began to increase due to the sorption of water molecules in the multilayer. The isosteric sorption heat of habanero pepper powder, which was determined using the Clausius-Clapeyron equation, decrease with an increase of moisture content, ranging from $4.86 \mathrm{KJ}$ mol-1 to 1,07 KJ mol1 and $7.59 \mathrm{KJ}$ mol-1 to 1,43 KJ mol-1.for adsorption and for desorption witn an equilibrium moisture content ranging from 5 to $45 \%$ (g water/g dry solids).

\section{Conclusions}

The isotherms of adsorption and desorption of habanero pepper dehydrated powder presented a sigmoid shape (Type II) at five different temperatures: 20, 25, 35, 45 and $55^{\circ}$ C. According to the results of this study, the GAB model presents a better fit of the 
Moisture sorption isotherms and isosteric heat sorption of habanero pepper (Capsicum chínense) dehydrated powder

experimental results of the sorption isotherms of the habanero pepper powder with a $\mathrm{R}^{2}>$ 0.995 , SSE $<7.705$ and RMSE $<1.133$. Habanero pepper powder was less hygroscopic as the temperature decreased. This behavior of sorption can be attributed to the low solubility nature of carbohydrates and bioactive compounds present in habanero pepper powder with water molecules. Water activity values from 0.3 to 0.4 represent the optimum moisture content at which most dehydrated foods will have maximum shelf life. Therefore, considering 0.35 as the average water activity, among these values, the safest for dehydrated habanero pepper powder, the limit equilibrium moisture content for this product should be $7.38 \%, 7.13 \%, 6.79 \%, 6.50 \%$ and $6.04 \%$ at temperatures of $20{ }^{\circ} \mathrm{C}, 25{ }^{\circ} \mathrm{C}, 35^{\circ} \mathrm{C}$, $45{ }^{\circ} \mathrm{C}$ and $55{ }^{\circ} \mathrm{C}$ respectively, since above this moisture content, enzymatic oxidation, chemical instability and/or oxidation will begin proliferation of microorganisms. Regarding drying kinetics, according to the obtained results, it was concluded that the empirical models that best describe the dehydration kinetics for habanero orange bell pepper are Page and Newton.

\section{References}

[1] Rhim J. and Hong S. (2011). Effect of water activity and temperature on the color change of red pepper (Capsicum annuum L.) powder. Food Science and Biotechnology, 20, 215-222.

[2] Sganzerla M., Pereira C. J., Tavares de Melo A. M., and Texeira G. H. (2014). Fast method for capsaicinoids analysis from Capsicum chinense fruits. Volumen 64, October 2014, 718-725.

[3] Schmidt S. J. and Won L. J. (2012) Comparison Between Water Vapor Sorption Isotherms Obtained Using the New Dynamic Dewpoint Isotherm Method and those Obtained Using The Standard Saturated Salt Slurry Method, International Journal of Food Properties, 15:2, 236-248.

[4] Basu S., Shivhare U.S. and Mujumdar A.S. (2006). Models for Sorption Isotherms for Foods: A Review. Drying Technology. 24: 917-930.

[5] Tsotsas E. and Mujumdar A. S. (2014). Industrial Moisture and Humidity Measurement. Wiley-VCH Verlag GmbH and Co.

[6] Villegas Santiago J., Calderón S. M., Ragazzo S. A., Salgado C. M. A. and Luna S. G. (2011). Fluidized bed and tray drying of thinly sliced mango (Mangiferaindica) pretreated with ascorbic and citric acid. Journal of Food Science and Technology 46, 1296-1302.

[7] Brunauer, S., Deming, L.S., Deming, W.E. y Troller, E. 1940. On the theory of Van der Waals adsorption of gases. Journal of American Society, 62, 1723-1732.

[8] Kaleemullah S. y Kailapan R. 2004. Moisture Sorption Isotherms of Red Chillies. Biosystems Engineering 88 (1); 95-104. 